IRA-International Journal of Management \& Social Sciences

ISSN 2455-2267; Vol.03, Issue 03 (2016)

Institute of Research Advances

http://research-advances.org/index.php/RAJMSS

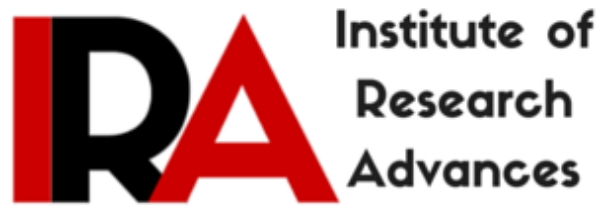

\title{
Creating learning organisation: An OD Practice
}

\section{Dr. Arpita Sarangi}

Faculty of MBA (OB\&HRM)

Institute of Management Bhubaneswar (IMB)

Gyan Vihar, Rasulghar, Bhubaneswar-10, Orissa, India.

DOI: http://dx.doi.org/10.21013/jmss.v3.n3.p3

\section{How to cite this paper:}

Sarangi, D. (2016). Creating learning organisation: An OD Practice. IRA-

International Journal of Management \& Social Sciences (ISSN 2455-2267), 3(3). doi:http://dx.doi.org/10.21013/jmss.v3.n3.p3

(C) Institute of Research Advances

\section{(cc) BY-NC}

This works is licensed under a Creative Commons Attribution-Non Commercial 4.0 International License subject to proper citation to the publication source of the work.

Disclaimer: The scholarly papers as reviewed and published by the Institute of Research Advances (IRA) are the views and opinions of their respective authors and are not the views or opinions of the IRA. The IRA disclaims of any harm or loss caused due to the published content to any party. 
Organizations where people continually expand their capacity to create the results they truly desire, where new and expansive patterns of thinking are nurtured, where collective aspiration is set free, and where people are continually learning to learn together (Senge,1990). A learning organisation(LO) is a place where people are continually discovering how they create their reality, and how they can change it.

\section{Learning means what}

- learning is considered sytonymous with "taking in information".

- real learning gets to the heart of what it means to be human.

- through learning we re-create ourselves.

- through learning we reperceive the world and our relationship to it.

- through learning we extend our capacity to create.

- learning organisations are those which are continually expanding their capacity to

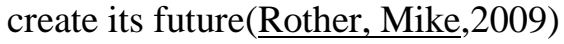

\section{Benefits}

The main benefits are;

- Maintaining levels of innovation and remaining competitive(McHugh, Groves,and Alker, 1998)

- Being better placed to respond to external pressures(McHugh, Groves, and Alker, 1998)

- Having the knowledge to better link resources to customer needs(Pedler, Burgogyne, and Boydell,1997)

- Improving quality of outputs at all levels

- Improving corporate image by becoming more people orientated.

- Increasing the pace of change within the organization.

\section{Learning organization}

The 'Learning Organisation' is an approach to OD, based on a particular view of organisational nature and purpose.

Organizations do not organically develop into learning organizations; there are factors prompting their change. As organizations grow, they lose their capacity to learn as company structures and individual thinking becomes rigid (Pedler, Burgogyne,and Boydell,1997). When problems arise, the proposed solutions often turn out to be only short term (single loop learning) and re-emerge in the future(Senge,1990). To remain competitive, many organizations have restructured, with fewer people in the company(Pedler, Burgogyne, and Boydell,1997). This means those who remain need to work more effectivelyTo create a competitive advantage, companies need to learn faster than their competitors and to develop a customer responsive culture (Keeffe, 2002). Argyris, 1999 identified that organizations need to maintain knowledge about new products and processes, understand what is happening in the outside environment and produce creative solutions using the knowledge and skills of all within the organization. This requires co-operation between individuals and groups, free and reliable communication, and a culture of trust. 


\section{The Metaphors for learning Organisation}

Three metaphors for the organisation and their organisational learning implications are briefly outlined below (CCH 2000, 40-800):

- The organisation as a machine

Managers will think of learning in terms of resources, incentives to perform and standards for performance. Employees will be encouraged to think in terms of effectiveness and efficiency, as specified by policies and procedures. Human Resource Development managers will specify skill needs and fill them by hiring those skills or by training workers to meet standards for performance.

- The organisation as open system

Emphasis is on facilitating employee competencies to provide resources for performance. Monitoring learning and performance is important. Employees negotiate learning to achieve goals, and progress is identified through feedback. Collaboration is fostered across boundaries. Human Resource Development managers seek to establish systems for self-directed learning and work as a partner with line managers and employees.

- The organisation as a brain/mind

Emphasis for managers is on modeling learning and fostering an environment of learning through job enrichment and cross functional teams. Employees are encouraged to diagnose organisational needs, to challenge assumptions and initiate learning which meets their own and the organisation's needs.

The emphasis for Human Resource Development managers is on the design of work and the integration of learning across the organisation, and on continuous learning".

The metaphor of the organisation as a brain/mind is consistent with Wheatley and Kellner-Rogers' (1998) view of the organisation as a living system. Within this context, they offer the following principles for practice in organisational Development:

- Participation is not a choice

Invite people into the process of rethinking, redesigning and restructuring the organisation - people support what they create.People need to be creatively involved in how their work gets done.The need to consider how the whole system is engaged over time. Otherwise, time will be spent on managing the unintended effects created by people feeling left out or ignored.

- Life always reacts to directives, it never obeys them

No matter how clear or visionary the message is, it can only elicit reactions, not straightforward compliance.

- We do not see "reality. We each create our own interpretation of what's real

If we engage with colleagues to share perceptions, we expect and even seek out the great diversity of interpretations that exist.If we remain curious about what someone else sees, and refrain from convincing them of our interpretation, we develop a richer view of what might be going on. We don't have to agree on an interpretation or hold identical values in order to agree on what needs to be done. 


\section{- To create better health in a living system, connect it to more of itself}

When a system is failing, or performing poorly, the solution will be discovered within the system, if more and better connections are created.The critical task for a leader is to increase the number, variety and strength of connections within the system.

Senge identifies the following five disciplines or levels of learning that must occur in order to become a learning organisation (Senge 1990).

Personal Mastery - creating an environment that encourages personal as well as organisational goals, so that both are in partnership. The commitment by an individual to the process of learning is known as personal mastery. There is a competitive advantage for an organisation whose workforce can learn quicker than the workforce of other organisations(Wang, and Ahmed. 2003)

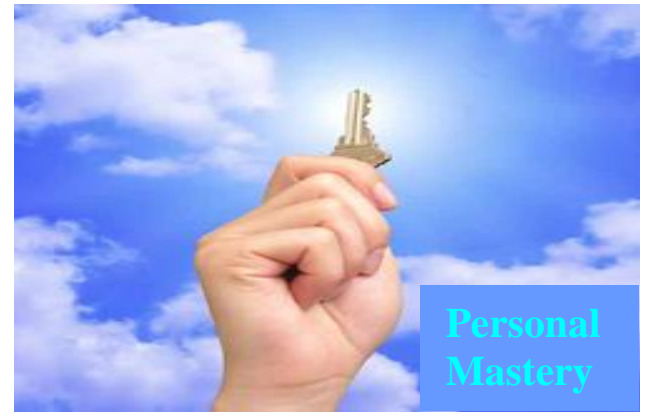

Individual learning is acquired through staff training and development (McHugh, Groves, and Alker, 1998), however learning cannot be forced upon an individual who is not receptive to learning. Research shows that most learning in the workplace is incidental, rather than the product of formal training, therefore it is important to develop a culture where personal mastery is practiced in daily life(Senge,1990).. A learning organization has been described as the sum of individual learning, but there must be mechanisms for individual learning to be transferred into organizational learning(Wang, and Ahmed,

Mental Models - identifying and understanding our internal pictures of the world in order to understand how they influence our decisions and behaviours. The assumptions held by individuals and organizations are called mental models (Senge,1990). To become a learning organization, these models must be challenged. Individuals tend to espouse theories, which are what they intend to follow, and theories-in-use, which are what they actually do. Similarly, organisations tend to have 'memories' which preserve certain behaviours. norms and values

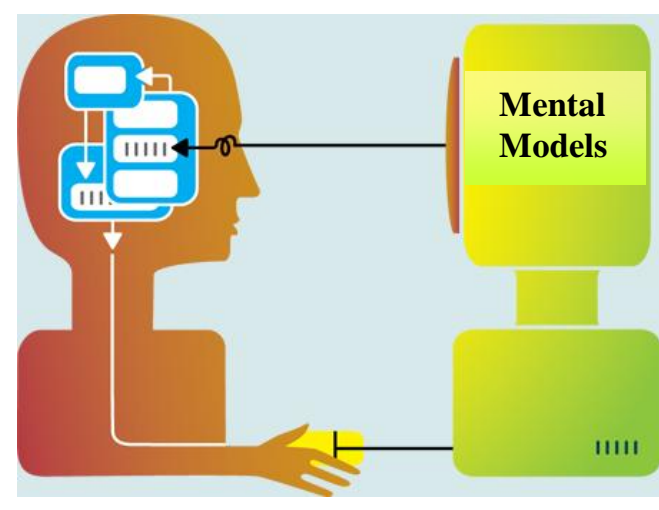
In creating a learning environment it is important to replace confrontational attitudes with an open culture (McHugh, Groves, and Alker, 1998) that promotes inquiry and trust. To achieve this, the learning organization needs mechanisms for locating and assessing organizational theories of action. Unwanted values need to be discarded in a process called 'unlearning',Wang and Ahmed,2003 refer to this as 'triple loop learning.' 
Shared Vision - the ability to develop shared images and visions of the future and a sense of common identit The development of a shared vision is important in motivating the staff to learn, as it creates a common identity that provides focus and energy for learning. The most successful visions build on the individual visions of the employees at all levels of the organisation(McHugh, Groves, and Alker, 1998), thus the creation of a shared vision can be hindered by traditional structures where the company

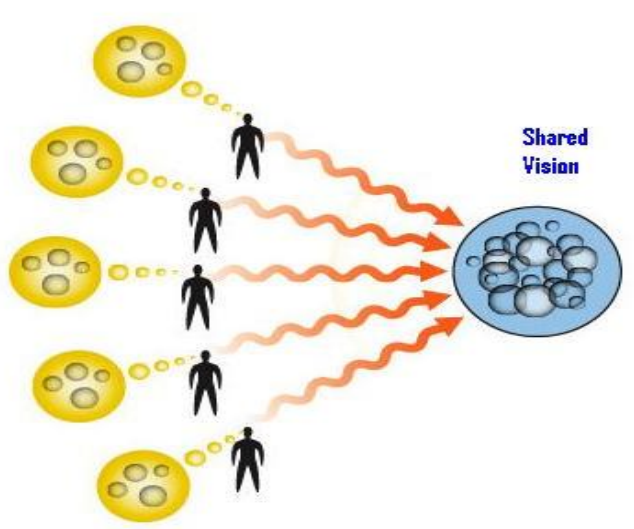
vision is imposed from above.

Therefore, learning organizations tend to have flat, decentralised organisational structures(Argyris,1999). The shared vision is often to succeed against a competitor, however (Senge,1990) states that these are transitory goals and suggests that there should also be long term goals that are intrinsic within the company.

Team Learning - achieving extraordinary performance and results through coordinated action and team skillsThe accumulation of individual learning constitutes Team learning. The benefit of team or shared learning is that staff grow more quickly and the problem solving capacity of the organization is improved

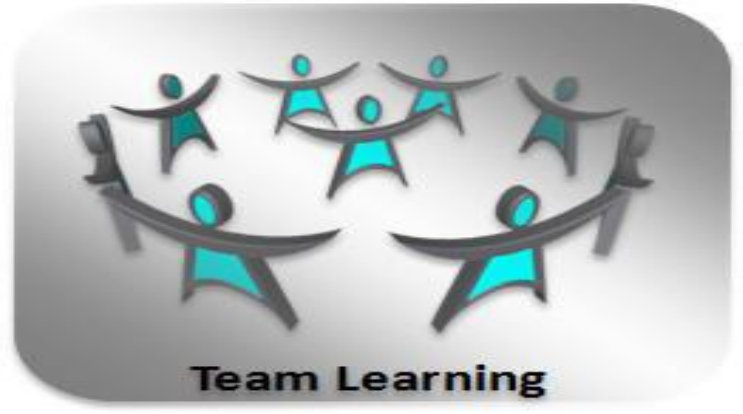

Learning organizations have structures that facilitate team learning with features such as boundary crossing and openness (Argyris,1999). Team learning requires individuals to engage in dialogue and discussion; therefore team members must develop open communication, shared meaning, and shared understanding. Learning organizations typically have excellent knowledge management structures, allowing creation, acquisition, dissemination, and implementation of this knowledge in the organisation.

Systems thinking - the ability to see the big picture, giving clarity and a definition to the underlying patterns and systems with the organisations. The idea of the learning organization developed from a body of work called systems thinking(Argyris, 1999). This is a conceptual framework that allows people to study businesses as bounded objects.

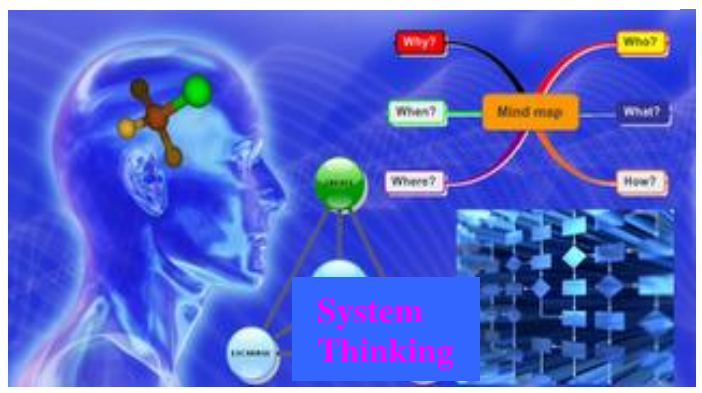


Learning organizations use this method of thinking when assessing their company and have information systems that measure the performance of the organization as a whole and of its various components (Argyris,1999). Systems thinking states that all the characteristics must be apparent at once in an organization for it to be a learning organization(Senge,1990). If some of these characteristics is missing then the organization will fall short of its goal. However O'Keeffe,2002 believes that the

This perspective illustrates the need for learning to occur at three levels: individual, team

and organisational. It also adopts the approach that organisations work the way they do because of how people think and interact and if changes do not occur at the individual and team level, then the organisation cannot change.

Garvin $(1993,80)$ defines a learning organisation as "an organisation skilled in creating, acquiring and transforming knowledge, and modifying its behaviour to reflect new knowledge and insights". Garvin describes five main elements to a learning organisation:

- Systematic problem solving

- Ongoing experimentation with new approaches

- Learning from the past and from own experiences

- Learning from others, particularly best practice

- Transferring knowledge quickly and efficiently throughout the organisation.

Dunoon $(2002,8)$ identifies a learning organisation as one which is concerned with "creating the conditions under which organisational members, jointly and individually, can make better sense of, or interpret, issues and opportunities they face that are not purely of a technical nature, and then take effective action". Therefore, one of the key ways in which an organisation can pursue its quest in becoming a learning organisation is to create a learning environment within which such learning can occur. The types of strategies that could be considered in creating such an environment include:

- Analysing how learning takes place

- Encouraging fast and smarter learning

- Providing a range of learning opportunities, including problem-solving groups, job rotations, mentoring schemes, action learning projects and communities of practice

- Learning from what goes wrong ie acknowledge both success and failure learning

- Encouraging experimental learning and risk taking

- Encouraging a climate of trust

- Increasing accountability for learning on an individual and group basis

- Setting up appropriate control and reward systems to encourage learning and recognize expertise.

Learning organisation is a journey not a destination to be reached, because if one views the organisation as a living human community, it is always evolving and unfolding. 


\section{Barriers}

Even within a learning organization, problems can stall the process of learning or cause it to regress. Most of them arise from an organization not fully embracing all the necessary facets. Once these problems can be identified, work can begin on improving them.

Some organizations find it hard to embrace personal mastery because as a concept it is intangible and the benefits cannot be quantified, personal mastery can even be seen as a threat to the organisation. This threat can be real, as Senge,1990 points out, that "to empower people in an unaligned organisation can be counterproductive". In other words, if individuals do not engage with a shared vision, personal mastery could be used to advance their own personal visions. In some organisations a lack of a learning culture can be a barrier to learning. An environment must be created where individuals can share learning without it being devalued and ignored, so more people can benefit from their knowledge and the individuals becomes empowered. A learning organization needs to fully accept the removal of traditional hierarchical structures(Keeffe, 2002).

Resistance to learning can occur within a learning organization if there is not sufficient buy-in at an individual level. This is often encountered with people who feel threatened by change or believe that they have the most to lose. They are likely to have closed mind sets, and are not willing to engage with mental models(Keeffe, 2002). Unless implemented coherently across the organization, learning can be viewed as elitist and restricted to senior levels. In that case, learning will not be viewed as a shared vision(McHugh, Groves, and Alker, 1998). If training and development is compulsory, it can be viewed as a form of control, rather than as personal development. Learning and the pursuit of personal mastery needs to be an individual choice, therefore enforced takeup will not work(Senge,1990).

\section{Conclusion}

This perspective is a pragmatic response to the many sceptics who question whether a learning organisation is possible to achieve. In terms of a model for increasing organisational capacity, the pursuit of the compatible learning elements and strategies have to be worthwhile endeavours.

\section{References}

1. Argyris, 1999. On Organizational Learning. 2nd Ed. Oxford: Blackwell Publishing.

2. CCH Australia Limited. November 1996-. Managing training and development. Sydney. CCH.

3. Dunoon, D. (2002) Rethinking leadership for the public sector Australian journal of public administration 61 (3) Sep 3-18.

4. Easterby-Smith, M. , Crossan, M., and Nicolini, D. 2000. Organizational learning: debates past, present and future. Journal of Management Studies. 37 (6) pp 783-796.

5. Garvin, D. (1993) Building a learning organization Harvard Business Review, USA.

6. McHugh, D., Groves, D. and Alker, A. 1998. Managing learning: what do we learn from a learning organization? The Learning Organization. 5 (5) pp.209-220.

7. O'Keeffe, 2002. Organizational Learning: a new perspective. Journal of European Industrial Training, 26 (2), pp. 130-141. 
8. Pedler, M., Burgogyne, J. and Boydell, T. 1997. The Learning Company: A strategy for sustainable development. 2nd Ed. London; McGraw-Hill.

9. Rother, Mike (2009). Toyota Kata. McGraw-Hill. ISBN 0071635238. http://books.google.com/books?id=_1lhPgAACAAJ\&dq=toyota+kata

10. Senge, P.M. 1990. The Fifth Discipline. London: Century Business.

11. Wang, C.L. and Ahmed, P.K. 2003. Organizational learning: a critical review. The learning organization, 10 (1) pp. 8-17.

12. Wheatley, Margaret J. \& Kellner-Rogers, Myron, (1996),: The irresistible future of organizing,[Online],

Available:

http://www.margaretwheatley.com/articles/irresistiblefuture.html 